\title{
Soft consensus model for the group fuzzy AHP decision making
}

\author{
Petra Grošelj ${ }^{1, \dagger}$ and Lidija Zadnik Stirn ${ }^{1}$ \\ ${ }^{1}$ Biotechnical Faculty, University of Ljubljana, Jamnikarjeva 101, 1000 Ljubljana, \\ Slovenia \\ E-mail: 〈\{petra.groselj, lidija.zadnik\}@bf.uni-lj.si〉
}

\begin{abstract}
The fuzzy analytic hierarchy process (AHP) is an extension to the classical AHP that enables dealing with the impreciseness and vagueness of judgments. It has been frequently used for handling complex decision making problems that demand a group rather than a single decision maker. Group decision making aggregates the judgments of individuals into a joint decision. Although consensus is the desired result in group decision making, it is difficult to achieve due to the diversity of opinions, knowledge and experiences of the decision makers. Therefore, the concept of soft consensus can be applied. We propose a new soft consensus based model for fuzzy AHP group decision making. The judgments in the model are presented as triangular fuzzy numbers. The closeness between judgments of two decision makers is measured by the individual fuzzy consensus index which in turn is based on the compatibility index from classical AHP. In each iteration, two decision makers with the most dissimilar opinions are identified and their judgments are adapted. The process is repeated until the desired consensus level is reached. The model can also take into account the weights of importance of individual decision makers. A fuzzy extension of the geometric mean method is employed for deriving fuzzy weights from a group fuzzy pairwise comparison matrix. The application of the model is provided in an example from the literature.
\end{abstract}

Keywords: fuzzy analytic hierarchy process, group decision making, triangular fuzzy numbers, soft consensus model

Received: October 10, 2016; accepted: March 24, 2017; available online: March 31, 2017

DOI: $10.17535 /$ crorr. 2017.0013

\section{Introduction}

The analytic hierarchy process (AHP) [1] is a multi-criteria method that has been frequently used to handle complex decision making problems [2-9]. It is based on a hierarchical structure. Besides classical AHP, where a 1-9 scale is applied, fuzzy AHP [10] which combines the classical AHP and the fuzzy set theory is often used in applications. Fuzzy AHP should be applied when the pairwise comparisons are

$\dagger$ Corresponding author 
imprecise because decision makers are unable to make exact preferences due to some unclear and indefinite information in the decision making process [11].

Complex and comprehensive problems often, rather than a single decision maker, demand a group of decision makers with various experiences, expertise and perspectives. In group decision making process individual judgments are aggregated into group decisions. There are several possibilities as to achieving the joint decision $[12,13]$. Consensus is the most desired result that can be reached through an iterative dynamic process. In each round, decision makers adapt their preferences according to advice given by a moderator or the results of the consensus model. There are several consensus models in classical AHP [14-20]. However, consensus is difficult due to a diversity of opinions by the decision makers. Therefore, the soft consensus [21, 22] is one possibility in overcoming the demand for complete agreement between decision makers.

The aim of the paper is to propose a new model for aggregating individual fuzzy judgments into a group of fuzzy judgments. In the iterative process, a soft consensus between decision makers is reached. First, we provide the necessary groundwork of fuzzy AHP. Then, we present new definitions and the algorithm of the new model. The model is applied to a known numerical example from the literature. Finally, some conclusions are provided.

\section{Fuzzy AHP}

AHP is based on the pairwise comparisons of objects on the same hierarchical level. In fuzzy AHP, linguistic terms such as equally important, slightly more important, moderately more important, strongly more important, etc. are used to express the pairwise comparisons. The linguistic terms are represented by the membership functions, most often of triangular or trapezoidal shape. In the paper, triangular fuzzy numbers (TFNs) (1) will be applied.

$$
\mu(x)=\left\{\begin{array}{cl}
\frac{x-l}{m-l}, & l \leq x \leq m \\
\frac{u-x}{u-m}, & m \leq x \leq u \\
0, & \text { otherwise }
\end{array}\right.
$$

There exist several different definitions of membership functions for the triangular fuzzy scale in the literature [23]. The triangular fuzzy scale that was used in our example is presented in Table 1. 


\begin{tabular}{|l|c|}
\hline \multicolumn{1}{|c|}{ Linguistic terms } & Triangular fuzzy scale \\
\hline Equally preferable (EQ) & $(1,1,1)$ \\
\hline Slightly preferable (SP) & $(2 / 3,1,3 / 2)$ \\
\hline Fairly preferable (FP) & $(1,3 / 2,2)$ \\
\hline Extremely preferable (EP) & $(3 / 2,2,5 / 2)$ \\
\hline Absolutely preferable (AP) & $(5 / 2,3,7 / 2)$ \\
\hline
\end{tabular}

Table 1: Triangular fuzzy scale

In applying the extension principle [24] to arithmetic operations, it is then possible to define fuzzy arithmetic operations.

Pairwise comparisons in fuzzy AHP are presented in the fuzzy comparison matrix:

$$
A=\left[\begin{array}{cccc}
(1,1,1) & \left(l_{12}, \mathrm{~m}_{12}, u_{12}\right) & \cdots & \left(l_{1 n}, \mathrm{~m}_{1 n}, u_{1 n}\right) \\
\left(l_{21}, \mathrm{~m}_{21}, u_{21}\right) & (1,1,1) & \cdots & \left(l_{2 n}, \mathrm{~m}_{2 n}, u_{2 n}\right) \\
\vdots & \vdots & \ddots & \vdots \\
\left(l_{n 1}, \mathrm{~m}_{n 1}, u_{n 1}\right) & \left(l_{n 2}, \mathrm{~m}_{n 2}, u_{n 2}\right) & \cdots & (1,1,1)
\end{array}\right]
$$

The weights $\mathrm{w}_{i}, i=1, \ldots, n$ derived from the fuzzy comparison matrix are fuzzy or crisp. Among the many methods for deriving weights from the fuzzy comparison matrix found in the literature [10, 25-27], the extent analysis method [28] and its improved version, a modified extent analysis method [29-33], is the most popular. Their resulting weights are crisp. Its main drawback is that it may produce illogical zero weights [29]. In the paper, we use a fuzzy extension of the geometric mean method that was first introduced by Buckley [25] and later corrected by Enea and Piazza [34] (3). 


$$
\begin{aligned}
& w_{i}=\left(w_{i l}, w_{i m}, w_{i u}\right), i=1, \ldots, n \\
& w_{i l}=\min \left\{\begin{array}{cc}
\sqrt[n]{\prod_{j=1}^{n} a_{i j}} & a_{k j} \in\left[l_{k j}, u_{k j}\right], \forall \mathrm{j}>\mathrm{k} \\
\sum_{k=1}^{n} \sqrt[n]{\prod_{j=1}^{n} a_{k j}} & a_{j k}=\frac{1}{a_{k j}}, \forall \mathrm{j}<\mathrm{k} \\
a_{j j}=1, \forall \mathrm{j}
\end{array}\right\} \\
& w_{i m}=\frac{\sqrt[n]{\prod_{j=1}^{n} m_{i j}}}{\sum_{k=1}^{n} \sqrt[n]{\prod_{j=1}^{n} m_{k j}}} \\
& w_{i u}=\max \left\{\begin{array}{cc}
\sqrt[n]{\prod_{j=1}^{n} a_{i j}} & a_{k j} \in\left[l_{k j}, u_{k j}\right], \forall \mathrm{j}>\mathrm{k} \\
\sum_{k=1}^{n} \sqrt[n]{\prod_{j=1}^{n} a_{i j}} & a_{j k}=\frac{1}{a_{k j}}, \forall \mathrm{j}<\mathrm{k} \\
a_{j j}=1, \forall \mathrm{j}
\end{array}\right\}
\end{aligned}
$$

The middle values of the weights are normalized geometric means of the $i$-th row of the middle values. The lower and the upper values of the weights are calculated according to the extension principle for the continuous functions.

\section{Model}

In the group decision making, individual TFN judgments are aggregated into the group TFN judgments and gathered into the group comparison matrix

$$
A^{\text {group }}=\left(a_{i j}^{\text {group }}\right)_{n \times n}, a_{i j}^{\text {group }}=\left(l_{i j}^{\text {group }}, \mathrm{m}_{i j}^{\text {group }}, \mathrm{u}_{i j}^{\text {group }}\right) .
$$

We present a new soft conse-nsus model for aggregating individual TFN judgments into the group TFN judgments. It is an extension to the fuzzy AHP of the peer-to-peer consensus reaching model [35], which is suitable for classical AHP. First we extent the compatibility index [36] to fuzzy AHP. 
Definition 1. Let $A_{p}=\left(\left(l_{i j}^{(p)}, \mathrm{m}_{i j}^{(p)}, \mathrm{u}_{i j}^{(p)},\right)\right)_{n \times n}$ and $A_{q}=\left(\left(l_{i j}^{(q)}, \mathrm{m}_{i j}^{(q)}, \mathrm{u}_{i j}^{(q)},\right)\right)_{n \times n}$ be two fuzzy comparison matrices. Then, their fuzzy compatibility index is defined as

$$
c_{f}\left(A_{p}, A_{q}\right)=\frac{1}{n^{2}} \sum_{i=1}^{n} \sum_{j=1}^{n} \frac{l_{i j}^{(p)} u_{j i}^{(\mathrm{q})}+4 m_{i j}^{(p)} m_{j i}^{(\mathrm{q})}+u_{i j}^{(p)} l_{j i}^{(\mathrm{q})}}{6} .
$$

If $A_{p}$ and $A_{q}$ are crisp comparison matrices with $l_{i j}^{(p)}=\mathrm{m}_{i j}^{(p)}=\mathrm{u}_{i j}^{(p)}$ and

$l_{i j}^{(\mathrm{q})}=\mathrm{m}_{i j}^{(\mathrm{q})}=\mathrm{u}_{i j}^{(\mathrm{q})}$, then $c_{f}\left(A_{p}, A_{q}\right)=c\left(A_{p}, A_{q}\right)$, where $c\left(A_{p}, A_{q}\right) \quad$ is a compatibility index of crisp comparison matrices. The compatibility index measures the compatibility or closeness of the fuzzy comparison matrices $A_{p}$

and $A_{q}$.

We employ the fuzzy compatibility index for measuring compatibility (closeness) between the opinions of two decision makers.

Definition 2. Let $A_{p}$ and $A_{q}$ be fuzzy comparison matrices of decision makers $D M_{p}$ and $D M_{q}$. Then, the individual fuzzy consensus index (IFCI) between decision makers $D M_{p}$ and $D M_{q}$ is defined as

$$
\operatorname{IFCI}_{p q}=c_{f}\left(A_{p}, A_{q}\right)
$$

The individual fuzzy consensus index holds the following properties:

\section{1. $\quad I F I_{p q} \geq 1$}

2. Symmetry: $I F C I_{p q}=I F C I_{q p}$

3. Reflexivity: $I_{F P}=1$

If $D M_{p}$ and $D M_{q}$ made similar judgments, they are more compatible, their fuzzy comparison matrices are close and $I F C I_{p q}$ is close to 1 . The more the judgements of $D M_{p}$ and $D M_{q}$ differ, the farther $I F C I_{p q}$ is from 1. If we require co- 
nsensus, than $I F C I_{p q}$ should equal 1 for all pairs of decision makers $D M_{p}$ and $D M_{q}$. Since we developed a soft consensus model, we set a threshold value $\varepsilon \geq 1$

Definition 3. [35] Decision makers $D M_{p}$ and $D M_{q}$ have acceptable consensus amongst each other if

$$
I F C I_{p q} \leq \varepsilon
$$

In classical AHP with crisp judgments, $\varepsilon=1.1$ [36] or $\varepsilon=1.01$ [35] is most often set. The threshold value $\varepsilon$ depends on the particular problem we are dealing with [35]. In fuzzy AHP, it depends on the TFN scale that is used. When using the TFN scale from Table 1, where 3.5 is the highest possible value, the threshold should be lower compared to the case of TFN where the highest value is 9 . In addition, the initial degree of consensus between decision makers influences the threshold. If the initial degree of consensus between decision makers is higher, the threshold may be lower. In the case when the initial degree of consensus between decision makers is low, it is hard to expect that they will reach a very low threshold. We propose to set the initial threshold at $\varepsilon=1.1$. If the initial IFCIs are all near the threshold, we could lower the threshold.

In our model, soft consensus between decision makers is reached using an iterative process. In each step, two decision makers with the highest disagreement amongst each other (with the highest IFCI) adapt their judgments. The process is repeated until all IFCIs are less or equal to the selected threshold $\varepsilon$.

Here we present the algorithm of the process in four steps:

Step 1. Set the number of iterations to zero $(t=0)$ and define the threshold value $\varepsilon$. Denote individual fuzzy comparison matrices $A_{k}^{0}, k=1, \ldots, m$ of decision makers $\mathrm{DM}_{1}, \ldots, \mathrm{DM}_{m}$ and the set of all pairs of decision makers

$$
P=\left\{\left(\mathrm{DM}_{1}, \mathrm{DM}_{2}\right), \ldots,\left(\mathrm{DM}_{1}, \mathrm{DM}_{\mathrm{m}}\right), \ldots,\left(\mathrm{DM}_{\mathrm{m}-1}, \mathrm{DM}_{\mathrm{m}}\right)\right\} .
$$

Then, specify the weights of importance of decision makers $\rho_{1}, \rho_{2}, \ldots, \rho_{m}$, since it is not necessary that all decision makers are equally important because they may have different knowledge, experiences and ranks. Set $\rho_{k}=1 / m$ if all decision makers are equally important. 
Step 2. Calculate $I F C I_{p q}^{t}$ for all $\left(D M_{p}, D M_{q}\right) \in P$. If $t \geq T$ or $\operatorname{IFCI}_{p q}^{t} \leq \varepsilon$ for all $\left(D M_{p}, D M_{q}\right) \in P$ then go to Step 4. Otherwise, continue to Step 3.

Step 3. Identify two the most incompatible decision makers $D M_{p}$ and $D M_{q}$ with $I F C I_{p q}^{t}=\max _{\left(D M_{k}, D M_{l}\right) \in P}\left\{I F C I_{k l}^{t}\right\}$. Define new individual fuzzy comparison matrices $A_{k}^{t+1}=\left(a_{i j}^{(k) t}\right)$ (7) so that only the fuzzy comparison matrices of decision makers $D M_{p}$ and $D M_{q}$ undergo the change and all other individual fuzzy comparison matrices remain the same as in the previous iteration.

$$
a_{i j}^{(k) t+1}=\left\{\begin{array}{cc}
\left(a_{i j}^{(k) t}\right)^{\alpha_{k}^{t}}\left(a_{i j}^{(\mathrm{q}) t}\right)^{1-\alpha_{k}^{t}}, & k=p \\
\left(a_{i j}^{(k) t}\right)^{\alpha_{k}^{t}}\left(a_{i j}^{(\mathrm{p}) t}\right)^{1-\alpha_{k}^{t}}, & k=q, \\
a_{i j}^{(k) t}, & k \neq p, q
\end{array}\right.
$$

New fuzzy comparison matrices of decision makers $D M_{p}$ and $D M_{q}$ are composed of their fuzzy comparison matrices from the previous iteration. The portion of DM's preserved judgments depends on the weight $\alpha_{p}^{t}(8)$ :

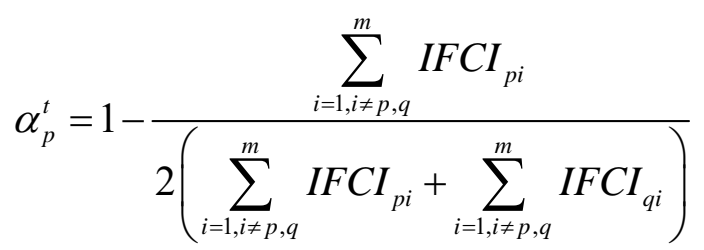

Set $t=t+1$ and return to Step 2 . 
Step 4. Denote the final individual fuzzy comparison matrices

$$
A_{k}^{*}=A_{k}^{t}, A_{k}^{*}=\left(\left(l_{i j}^{(k) *}, \mathrm{~m}_{i j}^{(k) *}, \mathrm{u}_{i j}^{(k) *}\right)\right)_{n \times n}, k=1, \ldots, m
$$

Define the group fuzzy comparison matrix $A^{\text {group }}=\left(a_{i j}^{\text {group }}\right)_{n \times n}$ by the weighted geometric mean of the final individual fuzzy comparison matrices

$$
a_{i j}^{\text {group }}=\left(\prod_{k=1}^{m}\left(l_{i j}^{(k) *}\right)^{\rho_{k}}, \prod_{k=1}^{m}\left(m_{i j}^{(k) *}\right)^{\rho_{k}}, \prod_{k=1}^{m}\left(u_{i j}^{(k) *}\right)^{\rho_{k}}\right) .
$$

Apply the fuzzy extension of the geometric mean method (3) to obtain the final group priority vector $\left(w_{1}, \ldots, w_{n}\right)$ from the group fuzzy comparison matrix

$$
A^{\text {group }}=\left(a_{i j}^{\text {group }}\right)_{n \times n} .
$$

The main part of the algorithm is Step 3. In each iteration, only the fuzzy comparison matrices of the most incompatible decision makers are changed. All other fuzzy comparison matrices remain unchanged. The fuzzy comparison matrices of the most incompatible decision makers are changed in the way that they become more similar. New fuzzy comparison matrices of decision makers

$D M_{p}$ and $D M_{q}$ are composed of their fuzzy comparison matrices from previous iteration (7).

The portion of $D M_{p}$ 's preserved judgments depends on the weight $\alpha_{p}^{t}(8)$ [35].

The weight of judgment preservation $\alpha_{p}^{t}$ is based on the degree of consensus between the $D M_{p}$ and all the other unselected decision makers (all decision makers except $p$ and $q$ ) and is calculated as the sum of IFCIs between the selected decision maker $p$ and all the other unselected decision makers:

$$
\sum_{i=1, i \neq p, q}^{m} I F C I_{p i}
$$


This sum is lower if $D M_{p}$ is more compatible with the other unselected decision makers. The fraction

$$
\frac{\sum_{i=1, i \neq p, q}^{m} I_{p C I_{p i}}}{\left(\sum_{i=1, i \neq p, q}^{m} I F C I_{p i}+\sum_{i=1, i \neq p, q}^{m} I F C I_{q i}\right)}
$$

from equation (8) is smaller and $\alpha_{p}^{t}$ is higher if the compatibility of $D M_{p}$ with the other unselected decision makers is higher than the compatibility of $D M_{q}$ with the other unselected decision makers. To ensure that the changes in the judgements of decision makers are not too large, factor 2 is added to the denominator in equation (8), which ensures that

$\alpha_{p}^{t} \in(0.5,1)[35]$.

\section{Example}

We apply the presented model to the example which was already discussed by several authors [10, 28, 37-39]. At a university, the post of professor of operations research is vacant. A committee of three members is therefore installed to give advice as to which applicant A, B or C is best qualified for the post. They have

identified four decision criteria: mathematical creativity $C_{1}$, creativity in imple-

mentations $C_{2}$, administrative capabilities $C_{3}$, and human maturity $C_{4}$. Here we will discuss only the relative importance of the four decision criteria. We presume that if one member does not make one pairwise comparison, it is equal to the pairwise comparison of the other members. Pairwise comparisons of the three committee members are presented in the following comparison matrices 


$$
\begin{aligned}
& A_{1}=\left[\begin{array}{cccc}
(1,1,1) & (2 / 3,1,3 / 2) & (2 / 3,1,3 / 2) & (2 / 7,1 / 3,2 / 5) \\
(2 / 3,1,3 / 2) & (1,1,1) & (5 / 2,3,7 / 2) & (2 / 3,1,3 / 2) \\
(2 / 3,1,3 / 2) & (2 / 7,1 / 3,2 / 5) & (1,1,1) & (2 / 5,1 / 2,2 / 3) \\
(5 / 2,3,7 / 2) & (2 / 3,1,3 / 2) & (3 / 2,2,5 / 2) & (1,1,1)
\end{array}\right] \\
& A_{2}=\left[\begin{array}{cccc}
(1,1,1) & (2 / 5,1 / 2,2 / 3) & (2 / 3,1,3 / 2) & (2 / 7,1 / 3,2 / 5) \\
(3 / 2,2,5 / 2) & (1,1,1) & (5 / 2,3,7 / 2) & (2 / 3,1,3 / 2) \\
(2 / 3,1,3 / 2) & (2 / 7,1 / 3,2 / 5) & (1,1,1) & (2 / 5,1 / 2,2 / 3) \\
(5 / 2,3,7 / 2) & (2 / 3,1,3 / 2) & (3 / 2,2,5 / 2) & (1,1,1)
\end{array}\right] \\
& A_{3}=\left[\begin{array}{cccc}
(1,1,1) & (3 / 2,2,5 / 2) & (2 / 3,1,3 / 2) & (2 / 5,1 / 2,2 / 3) \\
(2 / 5,1 / 2,2 / 3) & (1,1,1) & (5 / 2,3,7 / 2) & (3 / 2,2,5 / 2) \\
(2 / 3,1,3 / 2) & (2 / 7,1 / 3,2 / 5) & (1,1,1) & (2 / 5,1 / 2,2 / 3) \\
(3 / 2,2,5 / 2) & (2 / 5,1 / 2,2 / 3) & (3 / 2,2,5 / 2) & (1,1,1)
\end{array}\right]
\end{aligned}
$$

We presume that all three members are equally important. After calculating the initial IFCIs of all six pairs of decision makers, we decided to set the threshold value at $\varepsilon=1.01$. Since their opinions are similar, only four iterations are required to reach the desired level of consensus. The final fuzzy weights are presented in Table 2. Table 2 also presents the final fuzzy weights of three other methods from the literature.

\begin{tabular}{|l|c|c|c|c|}
\hline & Criterion 1 & Criterion 2 & Criterion 3 & Criterion 4 \\
\hline $\begin{array}{l}\text { Soft } \\
\text { consensus } \\
\text { model }\end{array}$ & $(0.142,0.185,0.240)$ & $(0.260,0.328,0.398)$ & $(0.118,0.150,0.194)$ & $(0.268,0.336,0.403)$ \\
\hline$[10]$ & $(0.149,0.194,0.256)$ & $(0.235,0.319,0.431)$ & $(0.112,0.140,0.180)$ & $(0.263,0.347,0.451)$ \\
\hline$[38]$ & $(0.17,0.19,0.22)$ & $(0.260,0.32,0.37)$ & $(0.13,0.14,0.16)$ & $(0.30,0.35,0.39)$ \\
\hline$[38]$ & $(0.150,0.194,0.223)$ & $(0.260,0.318,0.397)$ & $(0.139,0.139,0.144)$ & $(0.314,0.349,0.374)$ \\
\hline
\end{tabular}

Table 2: Final results of our model and the results three other methods

The results show that criteria $C_{4}$ and $C_{2}$ are more important than $C_{1}$ and $C_{3}$. The results of our new model are similar to the results of several methods that are already known from the literature, which indicates that our model produces logical weights and does not have any major deficiencies.

The most common aggregating approach in the group fuzzy AHP includes minimal lower and maximal upper values [40-42] that may result in impractical 
outcomes of TFNs with very wide support. Our model provides a novel approach that provides decision makers with insight into the iterative process of aggregating their judgments. In each iteration, only two decision makers are required to adapt their judgments, which is an advantage especially in a larger group of decision

makers. The suitable definition of weights $\alpha_{p}^{t}$ (8) assures that their judgments are not significantly altered, which promises decision makers higher satisfaction with the final results.

\section{Conclusions}

In the paper, we have presented a new soft consensus model for aggregating individual TFN judgments into group TFN judgments. The presented example and our analysis of other examples that are not presented here show that the final weights derived by our model are proper and logical. Unlike several known methods for deriving weights in group fuzzy AHP, the proposed model allows decision makers to understand how their opinion differs from the opinions of other decision makers. They can gradually adapt their judgments to achieve a desired degree of consensus. However, in future work, the model should be upgraded with the possibility that some individual pairwise comparisons are missing or that decision makers refuse to adapt their judgments.

\section{Acknowledgment}

Petra Grošelj would like to acknowledge the Slovenian Research Agency for its financial support in the framework of the program P4-0059.

\section{References}

[1] Anis, A., Islam, R. (2015). The application of analytic hierarchy process in higher-learning institutions: a literature review. Journal for International Business and Entrepreneurship Development, 8, 166-182.

[2] Boender, C.G.E., de Graan, J.G., Lootsma, F.A (1989). Multi-criteria decision analysis with fuzzy pairwise comparisons. Fuzzy Sets and Systems, 29, 133143.

[3] Buckley, J.J. (1985). Fuzzy hierarchical analysis. Fuzzy Sets and Systems 17, 233-247.

[4] Büyüközkan, G., Feyzıõlu, O. (2004). A fuzzy-logic-based decision-making approach for new product development. International Journal of Production Economics, 90, 27-45. 
[5] Chai, J., Liu, J.N.K., Ngai, E.W.T. (2013). Application of decision-making techniques in supplier selection: a systematic review of literature. Expert Systems with Applications, 40, 3872-3885.

[6] Chandio, I.A., Matori, A.N.B., WanYusof, K.B., Talpur, M.A.H., Balogun, A.-L., Lawal, D.U. (2013). GIS-based analytic hierarchy process as a multicriteria decision analysis instrument: a review. Arabian Journal of Geosciences, 6, 3059-3066.

[7] Chang, D.-Y. (1996). Applications of the extent analysis method on fuzzy AHP. European Journal of Operational Research, 95, 649-655.

[8] Deng, H. (1999). Multicriteria analysis with fuzzy pairwise comparison. International Journal of Approximate Reasoning, 21, 215-231.

[9] Do, Q.H., Chen, J.F. (2013). An evaluation of teaching performance: the fuzzy AHP and comprehensive evaluation approach. WSEAS Transactions on Information Science and Applications, 10, 90-99.

[10] Dong, Q., Cooper, O. (2016). A peer-to-peer dynamic adaptive consensus reaching model for the group AHP decision making. European Journal of Operational Research, 250, 521-530.

[11] Dong, Y., Zhang, G., Hong, W.-C., Xu, Y. (2010). Consensus models for AHP group decision making under row geometric mean prioritization method. Decision Support Systems, 49, 281-289.

[12] Enea, M., Piazza, T. (2004). Project selection by constrained fuzzy AHP. Fuzzy Optimization and Decision Making, 3, 39-62.

[13] Escobar, M.T., Moreno-Jimenez, J.M. (2007). Aggregation of individual preference structures in AHP-group decision making. Group Decision and Negotiation, 16, 287-301.

[14] Govindan, K., Rajendran, S., Sarkis, J., Murugesan, P. (2015). Multicriteria decision making approaches for green supplier evaluation and selection: a literature review. Journal of Cleaner Production, 98, 66-83.

[15] Grošelj, P., Pezdevšek Malovrh, Š., Zadnik Stirn, L. (2011). Methods based on data envelopment analysis for deriving group priorities in analytic hierarchy process. Central European Journal of Operations Research, 19, 267-284.

[16] Grošelj, P., Zadnik Stirn, L. (2013). Between compromise and consensus in group decisions in forest management. Šumarski list, 137, 403-410.

[17] Grošelj, P., Zadnik Stirn, L., Ayrilmis, N., Kuzman, M.K. (2015). Comparison of some aggregation techniques using group analytic hierarchy process. Expert Systems with Applications, 42, 2198-2204.

[18] Heo, E., Kim, J., Boo, K.-J. (2010). Analysis of the assessment factors for renewable energy dissemination program evaluation using fuzzy AHP. Renewable and Sustainable Energy Reviews, 14, 2214-2220.

[19] Heo, E., Kim, J., Cho, S. (2012). Selecting hydrogen production methods using fuzzy analytic hierarchy process with opportunities, costs, and risks. International Journal of Hydrogen Energy, 37, 17655-17662. 
[20] Herrera-Viedma, E., Cabrerizo, F.J., Kacprzyk, J., Pedrycz, W. (2014). A review of soft consensus models in a fuzzy environment. Information Fusion, 17, $4-13$.

[21] Ishizaka, A., Nguyen, N.H. (2013). Calibrated fuzzy AHP for current bank account selection. Expert Systems with Applications, 40, 3775-3783.

[22] Jato-Espino, D., Castillo-Lopez, E., Rodriguez-Hernandez, J., CanterasJordana, J.C. (2014). A review of application of multi-criteria decision making methods in construction. Automation in Construction, 45, 151-162.

[23] Javanbarg, M.B., Scawthorn, C., Kiyono, J., Shahbodaghkhan, B. (2012). Fuzzy AHP-based multicriteria decision making systems using particle swarm optimization. Expert Systems with Applications, 39, 960-966.

[24] Kacprzyk, J., Zadrożny, S. (2010). Soft computing and Web intelligence for supporting consensus reaching. Soft Computing, 14, 833-846.

[25] Krejčí, J., Pavlačka, O., Talašová, J. (2016). A fuzzy extension of Analytic Hierarchy Process based on the constrained fuzzy arithmetic. Fuzzy Optimization and Decision Making, 1-22.

[26] Regan, H.M., Colyvan, M., Markovchick-Nicholls, L. (2006). A formal model for consensus and negotiation in environmental management. Journal of Environmental Management, 80, 167-176.

[27] Russo, R.d.F.S.M., Camanho, R. (2015). Criteria in AHP: a systematic review of literature. Procedia Computer Science, 55, 1123-1132.

[28] Saaty, T.L. (1980). The analytic hierarchy process. McGraw-Hill, New York.

[29] Saaty, T.L. (2006). Fundamentals of decision making and priority theory with the analytic hierarchy process. RWS Publications, Pittsburgh.

[30] Shafiee, M. (2015). A fuzzy analytic network process model to mitigate the risks associated with offshore wind farms. Expert Systems with Applications, $42,2143-2152$.

[31] Srdjevic, B., Srdjevic, Z., Blagojevic, B., Suvocarev, K. (2013). A two-phase algorithm for consensus building in AHP-group decision making. Applied Mathematical Modelling, 37, 6670-6682.

[32] Stam, A., Sun, M., Haines, M. (1996). Artificial neural network representations for hierarchical preference structures. Computers and Operations Research, 23, 1191-1201.

[33] Subramanian, N., Ramanathan, R. (2012). A review of applications of analytic hierarchy process in operations management. International Journal of Production Economics, 138, 215-241.

[34] Vaidya, O.S., Kumar, S. (2006). Analytic hierarchy process: an overview of applications, European Journal of Operational Research, 169, 1-29.

[35] Van Laarhoven, P.J.M., Pedrycz, W. (1983). A fuzzy extension of Saaty's priority theory. Fuzzy Sets and Systems, 11, 199-227.

[36] Wang, Y.-M., Elhag, T.M.S. (2006). On the normalization of interval and fuzzy weights, Fuzzy Sets and Systems, 157, 2456-2471. 
[37] Wang, Y.-M., Elhag, T.M.S., Hua, Z. (2006). A modified fuzzy logarithmic least squares method for fuzzy analytic hierarchy process. Fuzzy Sets and Systems, 157, 3055-3071.

[38] Wang, Y.-M., Luo, Y., Hua, Z. (2008). On the extent analysis method for fuzzy AHP and its applications. European Journal of Operational Research, 186, 735-747.

[39] Wu, Z., Xu, J. (2012). A consistency and consensus based decision support model for group decision making with multiplicative preference relations. Decision Support Systems, 52, 757-767.

[40] Yeh, J.-M., Kreng, B., Lin, C. (2001). A consensus approach for synthesizing the elements of comparison matrix in the Analytic Hierarchy Process. International Journal of Systems Science, 32, 1353-1363.

[41] Zadeh, L.A. (1975). The concept of a linguistic variable and its application to approximate reasoning-I. Information Sciences, 8, 199-249.

[42] Zhu, K.-J., Jing, Y., Chang, D.-Y. (1999). A discussion on Extent Analysis Method and applications of fuzzy AHP. European Journal of Operational Research, 116, 450-456. 